\title{
UNIVERSITYOF
}

FORWARD

THINKING

WESTMINSTER用

WestminsterResearch

http://www.westminster.ac.uk/westminsterresearch

\section{Coupled CRLH transmission lines for compact and high \\ selectivity bandpass filters}

Ibrahim, A.A., Abdalla, M.A. and Budimir, D.

This is the peer reviewed version of the following article: Ibrahim, A.A., Abdalla, M.A. and Budimir, D. (2017) Coupled CRLH transmission lines for compact and high selectivity bandpass filters, Microwave and Optical Technology Letters, 59 (6), pp. 12481251 , which has been published in final form at

https://dx.doi.org/10.1002/mop.30518

This article may be used for non-commercial purposes in accordance with Wiley Terms and Conditions for Self-Archiving.

The WestminsterResearch online digital archive at the University of Westminster aims to make the research output of the University available to a wider audience. Copyright and Moral Rights remain with the authors and/or copyright owners.

Whilst further distribution of specific materials from within this archive is forbidden, you may freely distribute the URL of WestminsterResearch: ((http://westminsterresearch.wmin.ac.uk/)).

In case of abuse or copyright appearing without permission e-mail repository@westminster.ac.uk 


\title{
Coupled CRLH Transmission Lines for Compact and High Selectivity Bandpass Filters
}

\author{
Ahmed A. Ibrahim and Mahmoud A. Abdalla Senior Member, IEEE, and Djuradj Budimir, Senior \\ Member, IEEE
}

\begin{abstract}
A compact size and high selective bandpass filter is presented in this paper. The filter is designed to serve at $3.5 \mathrm{GHz}$ with two transmission zeros at $3.35 \mathrm{GHz}$ and $3.85 \mathrm{GHz}$. The filter is designed as two gap capacitor coupled to coupled composite right left handed transmission lines. The coupled lines were designed to demonstrate a zeroth order phase at $3.5 \mathrm{GHz}$. Also, the transmission zeros were achieved as a consequence of the electrical / magnetic couplings between the two coupled transmission lines. The employed cell, filter design equations are emphasized. The filter S-parameters were extracted based on the circuit model, full wave simulation and experimental measurements. A good agreement between modeled, simulated and measured results is achieved. The measured centre frequency of the bandpass filter is 3.55 $\mathrm{GHz}$ and $100 \mathrm{MHz}$ bandwidth which is suitable for WiMAX applications. Also, the filter has low measured insertion loss which does not exceed $1 \mathrm{~dB}$ within passband. Finally, the filter has advantageous of compactness (size is only $20 \times 18 \mathbf{~ m m}^{2}$ ) which is only $50 \%$ compared to conventional non-selective one stage coupled line filter.
\end{abstract}

Index Terms-CRLH TL, Bandpass Filters, Coupled-Line Coupler.

\section{INTRODUCTION}

$\mathrm{M}$ icrowave bandpass filters play an important role in various $\mathrm{RF} / \mathrm{microwave}$ circuits and systems. With the rapid growth of microwave and millimeter wave communication systems, the band pass filter must have several requirements such as compact size, low insertion loss and low cost. In order to realize band pass filters, different configurations may be designed. Researchers designed band pass filters which are based on parallel-coupled lines. The planer structure of parallel coupled line is simple, easy of implemented and has low fabrication cost [1],[2]. Also, coupled microwave resonators are used as main block of designing sharp bandpass filters. Conventional coupled resonators filter uses two coupled half guided-wave long transmission lines as resonators [3]. However, at low microwave frequencies, the dimensions of the resonators are significantly large. Several ideas have been introduced to reduce the resonator size by modifying its structure like open loop folded half-wavelength resonator [4] and DGS structures [5]. To improve the selectivity of the filter,

Manuscript received at $10^{\text {th }}$ July 2016.

Ahmed A. Ibrahim is with Electronics and Communications Dept., Minia University, Egypt). He is post-doctoral follow in the Otto-von-GuerickeUniversität Magdeburg, Germany. number of transmission zeros (TZs) around the passband have to be employed. By achieving multiple transmission zeros, the filter ability to reject unnecessary bands is increased. Various design techniques have been reported to create TZs around the filter passband. [6]. Such approaches uses the extraction pole method [7], a structures which has $0^{\circ}$ between the feeding lines [8] and coupling which is between the source and the load [9][11]. The previous approaches usually need to produce coupling paths therefore; coupling matrix needs to be synthesized to produce the desired filter response.

Composite right left handed transmission lines (CRLH-TL) have been presented as novel transmission lines with backward wave propagation (characterized with anti-parallel phase and group velocities) [11],[12]. A consequence, they have nonlinear positive/negative zero phase shift. It has been shown in that two coupled CRLH transmission lines can have very high backward coupling that can reach $0 \mathrm{~dB}$ [13]. Thanks to these properties, compact microwave resonators [14] filters [15] - [17] and couplers [18] are designed.

In this paper, a compact bandpass filter is introduced. The filter is an air gap coupled to two identical coupled CRLH TLs. The filter is designed to have a centre frequency of $3.55 \mathrm{GHz}$ and $100 \mathrm{MHz}$ bandwidth which is suitable for WiMAX applications. Also the filter design has achieved two transmission zeros at $3.35 \mathrm{GHz}$ and $3.85 \mathrm{GHz}$. The proposed filter is simulated, fabricated and measured. A good agreement between modeled, simulated and measured result is achieved

\section{FILTER THEORY AND STRUCTURE}

The schematic circuit of the designed filter is based on two coupled CRLH TLs as shown in Fig. 1 (a). It is based on using two coupled CRLH lines with open circuit termination for each. The input / output are coupled to the two coupled CRLH lines through two air gap capacitors. The circuit model for the proposed filter is shown in Fig. 1 (b). In the equivalent circuit, $C_{L}$ and $L_{L}$ are referring to the loading left handed elements; $C_{R}$ and $L_{R}$ are the patristic elements of the hosting TL whereas $C_{m}$ and $\mathrm{L}_{\mathrm{m}}$ are the mutual capacitance and inductance, respectively. Finally, $\mathrm{C}_{\mathrm{ac}}$ is the coupling air gap capacitor.

The employed cell was designed to introduce a zero phase at

M. A. Abdalla is with the Electronic Engineering Department, MTC College, Cairo, Egypt (e-mail: maaabdalla@ieee.org).

D. Budimir is with the Wireless Communications Research Group, University of Westminster, London, UK. 
the desired center frequency calculated as

$\theta=\beta l=\beta_{l} d_{l}+\beta_{r} d_{r}=n \pi$
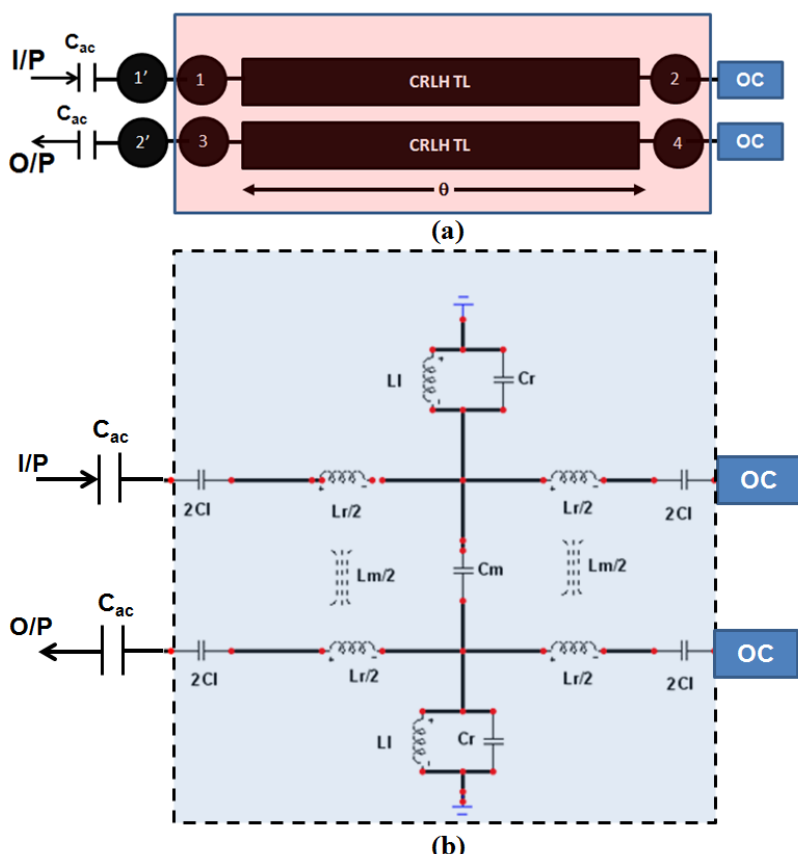

(b)

Fig. 1. The coupled composite right left handed bandpass filter.(a) The schematic circuit, (b) The equivalent circuit model of the proposed gap coupled CRLH filter, $\mathrm{C}_{\mathrm{ac}}=0.15 \mathrm{pF}, \mathrm{C}_{\mathrm{L}}=0.375 \mathrm{pF}, \mathrm{L}_{\mathrm{r}}=2.5 \mathrm{nH}, \mathrm{K}_{\mathrm{m}}=0.75$, $\mathrm{C}_{\mathrm{m}}=0.11 \mathrm{pF}, \mathrm{C}_{\mathrm{r}}=1.4 \mathrm{pF}, \mathrm{L}_{\mathrm{L}}=1.4 \mathrm{nH}$.

where $n$ is an integer. Zeroth order resonance occurs at $n=0$. where $\beta_{1}$ and $\beta_{\mathrm{r}}$ are the propagation constants of $\mathrm{LH}$ and $\mathrm{RH}$ sections, respectively, whereas $d_{l}$ and $d_{r}$ represent the lengths of these sections, respectively, while $l$ is the total length of the combined line. On the other hand, the achieved transmission zeros were achieved based on the backward CRLH coupling coefficients. This can be extracted using analysis of the proposed filter configuration using full wave analysis of coupled line CRLH couplers [18] as

$S_{21}=\alpha=\frac{A e^{-j \beta_{I} l}+B e^{-j \beta_{I I} l}}{A+B}$

$S_{31}=j \beta=\frac{A\left(\beta_{I}-\beta_{L H}\right) e^{-j \beta_{I} l}+B\left(\beta_{I I}-\beta_{L H}\right) e^{-j \beta_{I I} l}}{A\left(\beta_{I}-\beta_{L H}\right)+B\left(\beta_{I I}-\beta_{L H}\right)}$

$\beta_{I, I I}=\sqrt{\beta_{L H}^{2}-C_{B W}^{2}}$

For open circuit termination at port $2\left(\mathrm{~V}_{2}{ }^{-}=\mathrm{V}_{2}{ }^{+}\right)$and port 4 $\left(\mathrm{V}_{4}^{-}=\mathrm{V}_{4}^{+}\right)$, the coupled line coupler can serve as filter with

$S_{11}^{\prime}=\frac{\alpha^{2}}{1+\beta^{2}}$

$S_{21}^{\prime}=j\left(\frac{\alpha^{2} \beta}{1+\beta^{2}}+\beta\right)$

Following this circuit diagram, the employed CRLH cell was designed such as its geometry is shown in Fig. 2 (a). The loading capacitor $\left(C_{L}\right)$ is realized as 6 fingers interdigital capacitor whereas the inductor $\left(\mathrm{L}_{\mathrm{L}}\right)$ is realized using via hole stub. The synthesizing of these elements has been done based on the the formulas in [11] where they have been optimized using circuit model. Finally, the loading elements are calculated as given in Fig. 1 (b) and the distributed elements are in table I.

TABLE I

THE EMPLOYED CRLH CELL GEOMETRY DIMENSIONS

\begin{tabular}{|l|c|c|c|c|c|}
\hline \multicolumn{7}{|c|}{ Design parameters in mm } \\
\hline Parameter & $L$ & $W$ & $L c$ & $W c$ & $t c$ \\
\hline Dimension $(\mathrm{mm})$ & 18 & 20 & 4.8 & 2.8 & 0.3 \\
\hline Parameter & $s c$ & $L s$ & $p$ & $w f$ & \\
\hline Dimension $(\mathrm{mm})$ & 0.2 & 1.2 & 5.2 & 1.3 & \\
\hline
\end{tabular}

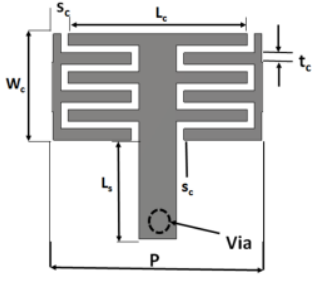

(a)

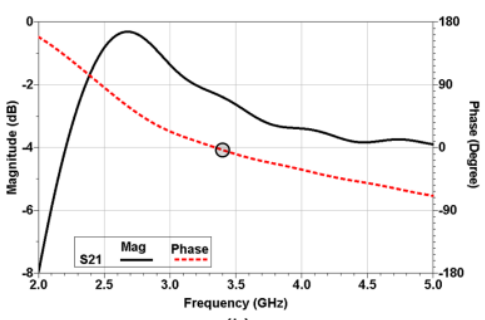

(b)
Fig. 2. The used CRLH cell (a) the cell geometry, (b) the simulated scattering parameters magnitudes.

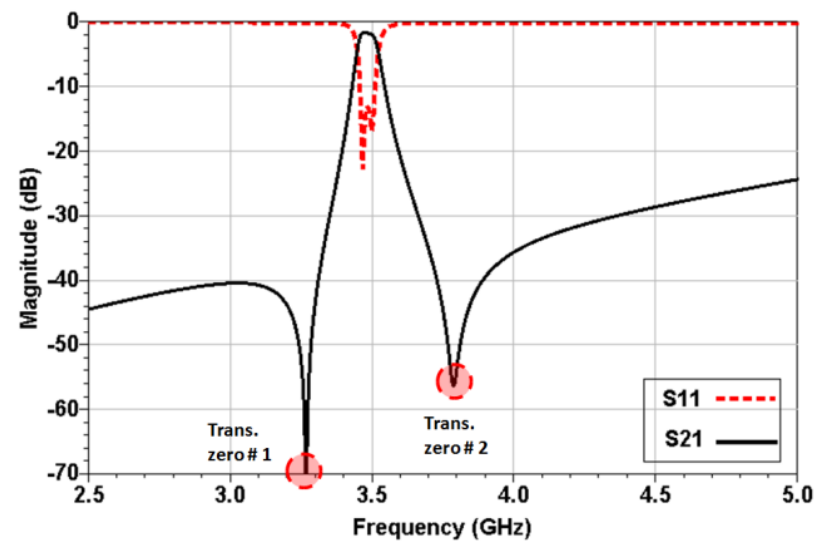

Fig. 3. The simulated scattering parameters magnitudes for the equivalent circuit model.

The zeroth order mode of the designed cell has been confirmed by simulating 2 port CRLH cell. The simulated scattering magnitudes of the cell are shown in Fig. 2 (b). As shown in the figure, the cell demonstrates zero phase at 3.4 $\mathrm{GHz}$. This result has been used later for optimizing the center frequency of the filter to be at $3.5 \mathrm{GHz}$. On the other hand, the simulated circuit model of the proposed filter is shown in Fig. 3. As shown in the figure, the filter is centered at $3.5 \mathrm{GHz}$ with insertion loss $=0.5 \mathrm{~dB}$ and return loss close to $18 \mathrm{~dB}$. Also, the filter has two transmission zeros at $3.3 \mathrm{GHZ}$ and $3.8 \mathrm{GHz}$. These two zeros are $-80 \mathrm{~dB}$ and $-60 \mathrm{~dB}$ at the two former frequencies, respectively.

\section{THE FILTER RESULTS}

The gap coupled coupled CRLH filter layout is shown in Fig. 4 (a). It is formed by using two air gap coupling capacitors to two coupled previously designed CRLH cells. The filter is printed on Rogers 6010 substrate with a relative dielectric constant of 10.2 with loss tangent of 0.0023 and a thickness of $1.27 \mathrm{~mm}$ and with $50 \Omega$ microstrip feed line. The fabricated 
filter prototype is shown in Fig. 4(b). The coupling length is only $4 \mathrm{~mm}$ whereas the filter size is $\left(20 \times 18 \mathrm{~mm}^{2}\right)$. The filter size comparison illustrates that the filter has $50 \%$

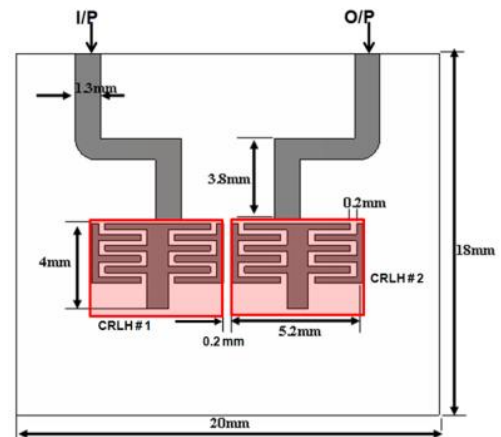

(a)

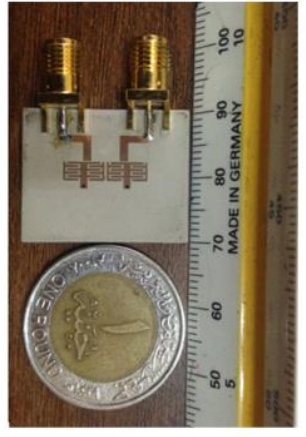

(b)
Fig. 4. The gap coupled CRLH filter (a) The 2D layout (b) The fabricated filter prototype.

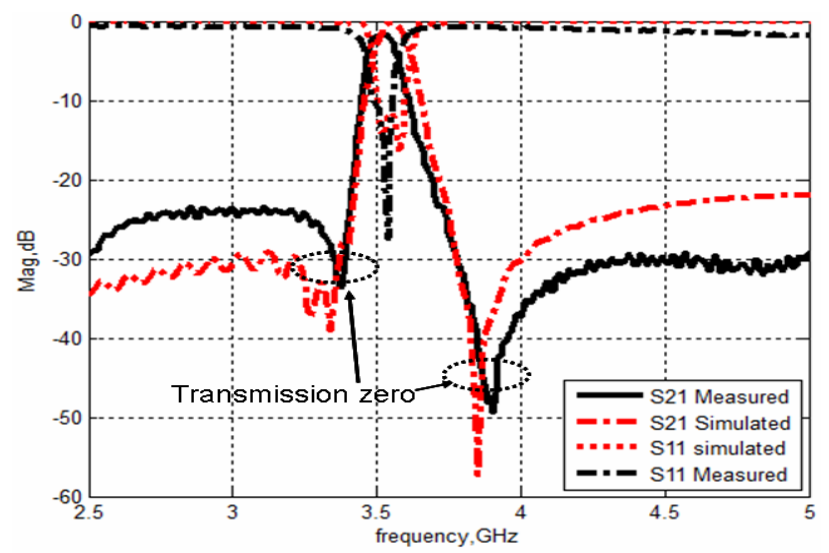

Fig. 5. The simulated and measured scattering parameter magnitudes of the proposed gap coupled CRLH filter.

size reduction than the conventional filter illustrated in [3].

The fabricated filter was tested by measuring the scattering parameter. The simulated and measured scattering parameters magnitudes of the proposed filters were compared to each other as illustrated in Fig. 5. It is clear that from the simulated results the proposed filter operates at $3.55 \mathrm{GHz}$ with bandwidth of 100 $\mathrm{MHz}$ and there are two transmission zeros at $3.35 \mathrm{GHz}$ and 3.85 GHz. These two transmission zeros are due to there is a coupling between input /output ports. In Table II, a comparison between the proposed filter and most recent published filter works with transmission zeros where our filter competitive characteristics are obvious.

TABLE II

COMPARISON BETWEEN THE PROPOSED FILTER AND MOST RECENT PUBLISHED WORK

\begin{tabular}{c|c|c|c|c|c|l}
\hline Ref & $\begin{array}{c}f_{o} \\
(\mathrm{GHz})\end{array}$ & $\begin{array}{c}\epsilon_{\mathrm{r} /} \\
\text { Thickness } \\
(\mathrm{mm})\end{array}$ & $\begin{array}{c}\mathrm{BW} \\
(\mathrm{GHz})\end{array}$ & $\mathrm{IL} / \mathrm{RL}$ & $\mathrm{TZs}$ & $\begin{array}{l}\text { Size } \\
(\mathrm{mm})\end{array}$ \\
\hline $\begin{array}{c}\text { This } \\
\text { Work }\end{array}$ & 3.55 & $10.2 / 1.27$ & 0.1 & $0.5 / 15$ & 2 & $10.6 \times 4$ \\
\hline$[2]$ & 2 & $6.15 / 1.52$ & 0.2 & $1.2 / 20$ & 0 & $48 \times 38$ \\
\hline$[9]$ & 4.32 & $2.56 / 0.77$ & 0.27 & $1.5 / 18$ & 3 & $16.3 \times 10.4$ \\
\hline$[15]$ & 4.35 & $22 / 1.57$ & 0.29 & $0.7 / 18$ & 1 & $6.07 \times 5.14$ \\
\hline$[16]$ & 3.5 & $10.2 / 1.27$ & - & $1 / 20$ & 1 & $12.8 \times 5.29$ \\
\hline
\end{tabular}

\section{CONCLUSION}

A compact second order bandpass filter has been presented. The bandpass filter is based on composite right left handed transmission line. The two resonators have been designed using only one composite right left handed unit cell. The filter has the advantage of compactness. The filter with a centre frequency of $3.55 \mathrm{GHz}$ and two transmission zeros at $3.35 \mathrm{GHz}$ and 3.85 $\mathrm{GHz}$ has been designed, simulated and measured. A Good agreement between simulated and measured result has been achieved. The filter shows low measured insertion loss which does not exceed $1 \mathrm{~dB}$ within passband. The designed filter is suitable for WiMAX applications.

\section{REFERENCES}

[1] Shih-Cheng Lin, "Coupled-Line Filters With Stub-Embedded Resonators Using Accurate Admittance-Transformer Feeds for Flexible Terminations"., IEEE Transaction on microwave Theory and Techniques, vol. 62, no. 12, pp. 2911-2922, 2014.

[2] Taejun Lim, Byung-Wook Min, Yongshik Lee, "Miniaturisation method for coupled-line bandpass filters with identical and minimal number of reactive elements", IET Microw. Antennas Propag, vol. 8, no. 14, pp. 1192-1197, 2014.

[3] Jia-Sheng Hong, Microstrip filters for RF/Microwave applications New York: J. Wiley \& Sons, $2^{\text {nd }}$ ed, 2011.

[4] C. Y. Chen, and C. Y. Hsu, "A simple and effective method for microstrip dual-band filters design", IEEE Microwave and Wireless Components Letters, vol.16, no., pp. 246-248, 2006.

[5] A. Boutejdar, W.A. Ellatif, A.A. Ibrahim, M. Challal, " A simple transformation from lowpass to bandpass filter using a new quasi-arrow head defected ground structure resonator and gap-J-inverter", Microwave and Optical Tech. Lett., vol. 58, no. 4, pp. 947-953, 2016.

[6] J. S. Hong and M. J. Lancaster, "Design of highly selective microstrip bandpass filters with a single pair of attenuation poles at finite frequencies," IEEE Trans. Microw. Theory Techn., vol. 48, no. 7, pp. 1098-1107, Jul. 2000.

[7] K. S. K. Yeo, M. J. Lancaster, and J. S. Hong, "The design of microstripsix-pole quasi-elliptic filter with linear phase response using extracted pole technique," IEEE Trans. Microw. Theory Techn., vol. 49, no. 2,pp. 321-327, Feb. 2001.

[8] C.-M. Tsai, S.-Y. Lee, and C.-C. Tsai, "Performance of a planar filter using a 0 feed structure," IEEE Trans. Microw. Theory Techn., vol 50, no. 10, pp. 2362-2367, Oct. 2002.

[9] H.Wang and Q. X. Chu, "A narrow-band hairpin-comb two-pole filter with source-load coupling," IEEE Microw.Wireless Compon. Lett., vol.20, no. 7, pp. 372-374, Jul. 2010.

[10] C. K. Liao and C. Y. Chang, "Design of microstrip quadruplet filters with source-load coupling," IEEE Trans. Microw. Theory Techn., vol.53, no. 7, pp. 2302-2308, Jul. 2005.

[11] C. Caloz and T. Itoh, Electromagnetic Metamaterials Transmission Line Theory and Microwave Applications. N Jersey: J. Wiley \& Sons,2006.

[12] G. V. Eleftheriades and K. G. Balmain, Negative Refractive Metamaterials. New Jersey: John Wiey \& Sons, 2005.

[13] H. V. Nguyen, and C. Caloz, "Generalized coupled mode approach of metamaterial CLCs: coupling theory, phenomenological explanation, and experimental demonstration," IEEE Trans. Microwave Theory and Tech., vol. 55, pp. 1029-1039, May 2007.

[14] Mahmoud A. Abdalla and Z. Hu, "Compact Metamaterial Coplanar Waveguide Ferrite Tunable Resonator, "IET Microwaves, Antennas \& Propagation, vol. 10, no. 4, pp. 406-412, 2016

[15] S. Karimian and Z. Hu, "Miniaturized composite right/left-handed stepped-impedance resonator bandpass filter," IEEE Microw. Wireless Compon. Lett., vol. 22, no. 8, pp. 421-423, Aug. 2012.

[16] H. Wen, L. Jin, and H. Chen, "Improved composite right/left handed transmission line metamaterials and its application in bandpass filters, "in Proc. Int. Workshop Microw. Millimeter Wave Circuits Syst.Technol., Apr. 2012, pp. 1-3.

[17] M. Fouad, M. A. Abdalla. "A new $\pi$-T generalized metamaterial NRI transmission line for a compact CPW triple BPF applications", IET Microwave Antenna Propag, vol. 8, no. 9, pp. 1097-1104, 2014. 
[18] M. A. Abdalla and Z. Hu, "Compact tunable single and dual mode ferrite left-handed coplanar waveguide coupled line couplers," IET Microwaves, Antennas \& Propagation, vol. 3, no. 4, pp. 695-702, 2009 